\title{
Novel popout with nonsense strings: Effects of predictability of string length and spatial location
}

\author{
KEVIN J. HAWLEY, WILLIAM A. JOHNSTON, and JAMES M. FARNHAM \\ University of Utah, Salt Lake City, Utah
}

\begin{abstract}
Recent studies have shown that when one of four expected words is replaced by a single unexpected word, the unexpected word may capture attention. In three experiments, we explored the generality of this effect. In each experiment, observers viewed arrays composed of four computergenerated "nonsense" strings. Accuracy of string localization was assessed after each array. Some strings, called familiar, appeared in many arrays, whereas others, called novel, appeared in only one. In each experiment, novel strings in arrays composed of one novel and three familiar strings were localized more accurately than were novel strings in arrays composed entirely of novel strings, and familiar strings in these arrays were localized less accurately than were familiar strings in arrays composed entirely of familiar strings. These two effects, termed novel popout and familiar sink-in, respectively, were observed even when novel and familiar strings were rendered less discriminable by holding their lengths constant (Experiment 2) and when familiar strings always appeared in the same spatial locations (Experiment 3 ). The data suggest that novel objects can capture attention even when the objects lack any clear linguistic referent, when they are superficially similar to the familiar objects that surround them, and when the spatial locations of familiar objects are completely predictable.
\end{abstract}

When navigating through a familiar environment, organisms are faced with the dual challenge of identifying both the regular or expected features of that environment as well as any unexpected or novel intrusions. Two processes seem to aid in the identification of familiar or expected stimuli. First, the perception of familiar or previously perceived stimuli may be enhanced via perceptual priming (e.g., Feustal, Shiffrin, \& Salasoo, 1983; Jacoby \& Dallas, 1981; Meyers, Schvaneveldt, \& Ruddy, 1975). Second, extensive familiarity with an environment may allow for the development of perceptual schemata that encode the regularities of that environment (e.g., Biederman, 1972; Friedman, 1979; Mandler, 1984; Rumelhart, Smolensky, McClelland, \& Hinton, 1986). Together, these processes allow an organism to rapidly and accurately identify the stable features of its environment. However, because these processes tend to bias perception toward what is familiar or expected, the organism can become relatively insensitive to environmental changes. Fortunately, this tendency appears to be counteracted by

\footnotetext{
This research was supported in part by a University of Utah Graduate Research Fellowship and by a 1991 APA Dissertation Research Award to the first author. Additional support was provided by Air Force Office of Scientific Research Grant 89-0275 to W.A.J. All of the experiments described in this paper were completed by the first author in partial fulfillment of the requirements for the doctoral degree at the University of Utah. We would like to thank Charles Folk, Tram Neill, and an anonymous reviewer for their helpful comments and suggestions regarding an earlier draft of this manuscript. Requests for reprints should be directed to K. J. Hawley, who is now at the Department of Psychology, 210 McAlester Hall, University of Missouri-Columbia, Columbia, MO 65211.
}

another phenomenon, called novel popout. Novel popout refers to the tendency for novel or unexpected stimuli in an array or scene to capture attention. By ensuring a degree of vigilance to environmental change, novel popout may provide a mechanism for the appropriate updating or revision of perceptual schemata.

Although a considerable amount of research has been directed toward an understanding of priming and schematic perception, the mechanisms underlying novel popout have only recently been addressed (e.g., Johnston, Hawley, \& Farnham, 1993; Johnston, Hawley, Plewe, Elliott, \& DeWitt, 1990). In a typical experiment (e.g., Johnston et al., 1990, Experiment 4) observers receive 200-msec glimpses of backward-masked four-word arrays. Familiar words appear many times across the series of arrays, whereas novel words appear only once. Three different combinations of novel and familiar words are employed. All-familiar arrays contain only familiar words, all-novel arrays contain only novel words, and one-novel arrays contain one novel word and three familiar words. The locations of both novel and familiar words vary randomly across arrays and, therefore, cannot be predicted in advance. Novel popout, assessed via accuracy of word localization following each array, manifests itself as two particular effects. First, localization accuracies for novel words in one-novel arrays are higher than for those in all-novel arrays, defining novel popout. Second, accuracies for familiar words in one-novel arrays tend to be lower than for those in all-familiar arrays, defining familiar sink-in. Together, these findings suggest that attention is shifted away from familiar words and 
toward the novel word in one-novel arrays. Occasionally, the effects of this shift can be great enough so that localization accuracy for the single novel word actually exceeds that for the familiar words that surround it (an effect termed within-array novel popout/familiar sink-in). ${ }^{1}$

The previously reported findings of Johnston et al. $(1990,1993)$ discredit several potential interpretations of novel popout. For example, novel popout is not attributable either to eye movements or to an active search for novel items, because the effect has been observed in displays exposed for only $33 \mathrm{msec}$. Novel popout is not easily attributable to familiarity-based figure-ground contrast, because a complementary popout for familiar words was not observed in displays composed of one familiar and three novel words. In addition, novel popout is unlikely to be the result of either perceptual satiation or memorial confusion for the familiar words, because localization accuracies for all-familiar arrays are normally higher than those for all-novel arrays. Finally, novel popout is not attributable to the perceptual fluency of individual familiar words, because novel words do not "pop out" from fields composed of words that have been repeated many times but never together. Instead, a lone novel word appears to capture attention only when it is imbedded in a field of words that have become highly interassociated, or perceptually "unitized," owing to their repeated presentation together.

Notwithstanding previous efforts to identify the conditions under which novel popout occurs, the overall generality of the effect remains unclear. In particular, three questions have often been raised in response to prior reports of novel popout. First, because all of the previously reported effects associated with novel popout have been obtained with the use of words as stimuli, it is not clear whether novel popout reflects a general sensitivity to perceptually incongruent information or is limited to linguistic or otherwise "meaningful" stimuli. Second, because novel popout has been observed in displays exposed for as briefly as $33 \mathrm{msec}$, it is possible that the effect occurs principally with stimuli that happen to be conspicuous in terms of some simple feature or superficial physical characteristic, such as length. Finally, because all of the previously reported studies of novel popout allowed the locations of familiar items to vary randomly, it is not clear whether novel popout generalizes to situations in which the locations of expected objects are predictable, a situation that characterizes the stable configurations of objects found in familiar environments. In the present research, we sought to extend the empirical foundations upon which a theory of novel popout would be based by addressing each of these questions.

\section{EXPERIMENT 1}

In Experiment 1, we examined whether novel-popout effects could be obtained with stimuli other than words. This was achieved by employing semirandom strings of graphics characters from the ASCII extended character set as stimuli. The use of such "nonsense" strings pro- vides two distinct advantages over other forms of nonverbal stimuli (e.g., nonwords or pictures). First, because observers have no previous experience with these objects, perceptual processes can be examined in a context that is relatively free from the influence of preexperimentally established schemata and expectancies. Instead, familiarity can be developed entirely within the experimental context. Second, because nonsense strings are not subject to the phonological and grammatical rules that govern the construction of linguistic stimuli, the construction of these objects can be tailored so that they share certain global characteristics, such as length.

Aside from the use of nonsense strings, the design of Experiment 1 was similar to that used by Johnston et al. (1990, Experiment 4). Observers viewed a long series of all-familiar, all-novel, and one-novel arrays. Familiarity with the familiar strings was established during a practice phase, and the relative perceptibility of familiar and novel strings in the various display compositions was assessed in a subsequent test phase. If novel popout represents a general tendency for attention to be captured by objects that are not associated with the field in which they appear, then the novel-popout and familiar-sink-in effects observed by Johnston et al. (1990, Experiment 4) should be replicated.

\section{Method}

Observers and Design. The observers were 36 undergraduate students from an introductory psychology course at the University of Utah. They participated in the experiment in return for extra credit toward a higher grade in their class. All reported normal or corrected-to-normal vision. Array composition (all-familiar, onenovel, and all-novel) was manipulated within observers in the test phase. Object type (novel vs. familiar) was an additional factor nested within the one-novel arrays.

Equipment and Stimuli. The observers served individually in a small room equipped with an IBM XT-compatible microcomputer, a keyboard, and a Samsung color monitor (Model MM-1464W) with a $P 22$ phosphor. Each observer wore headphones over which a low level of white noise was continuously broadcast in order to minimize external distractions. They sat facing the monitor from an approximate viewing distance of $60 \mathrm{~cm}$. The monitor provided most of the light in the room. The experiment was prepared and executed by using the PsyExper software system (Hawley, 1991).

The stimuli were 484 objects composed of nonalphanumeric characters from the ASCII extended character set. Each character, etched in white against a blue background, subtended visual angles of $0.60^{\circ}$ vertically and $0.28^{\circ}$ horizontally. A total of 60 different characters was used, with each character assigned to one or more of three groups. Characters in Group 1 were always used as the first character of each string, those in Group 2 comprised the middle characters of each string, and those in Group 3 were always the last character. Characters were assigned to each group on the basis of our judgment of the extent to which they formed good continuity with characters from the other two groups. For any given string, a single character was chosen at random from both Group 1 and Group 3, and two to five characters were chosen at random from Group 2. Thus, the individual strings varied from four to seven characters in length, with each character connected to the characters adjacent to it.

Procedure. An experimental session comprised a series of 384 trials. During each trial, an array of four rectangular boxes, hereafter referred to as locations, was centered on the monitor at all 
times. The entire array subtended approximate visual angles of $4.10^{\circ}$ vertically and $6.30^{\circ}$ horizontally. A character string could appear, centrally adjusted, in any of the four locations. As Figure 1 illustrates, each trial was composed of a sequence of four arrays: attention, mask, probe, and feedback. In an attention array, each of the four locations contained a different string. These strings were displayed for $183 \mathrm{msec}$ and were followed, $17 \mathrm{msec}$ later, by a masking array. This procedure yielded a virtual exposure of $200 \mathrm{msec}$ for each attention array. The masking array was displayed for $100 \mathrm{msec}$ and was followed, $500 \mathrm{msec}$ later, by a probe array. In the probe array, one of the strings from the attention array was displayed in all four locations. The observer's task was to indicate the particular location in which the probe string had appeared in the preceding attention array. This indication was made by pressing the appropriate key out of four on the numeric keypad of the keyboard. The spatial configuration of these keys matched that of the four array locations. The observers were instructed to be as accurate as possible in responding. The speed and accuracy of each response was scored by the computer. A response terminated a probe array and was followed, 17 msec later, by a feedback array in which the probe string reappeared for $1 \mathrm{sec}$ in its correct location. The next trial commenced 500 msec after the offset of the feedback array. After every block of 30 trials, the percentage of correct localizations for that block was displayed for $5 \mathrm{sec}$. At the end of the experiment, the observers answered a short questionnaire designed to measure their awareness of the differences in array composition. The observers were then debriefed and dismissed.

\section{Attention Array (183 ms)}

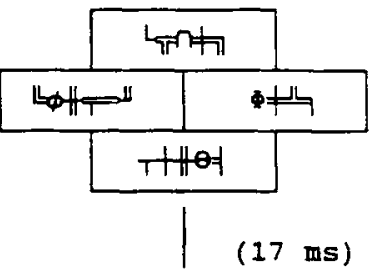

\section{Mask Array ( $100 \mathrm{~ms}$ )}

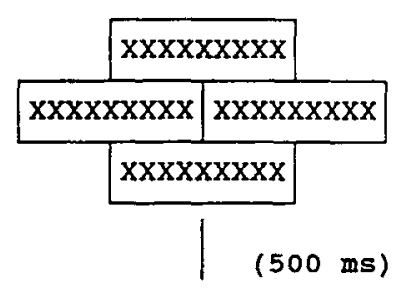

3. Probe Array (until response)

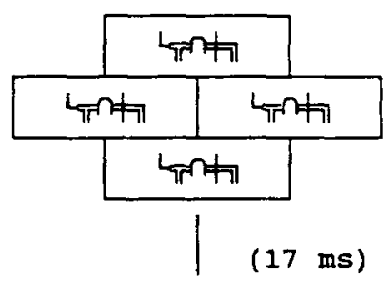

\section{Feedback Array} (1 s)

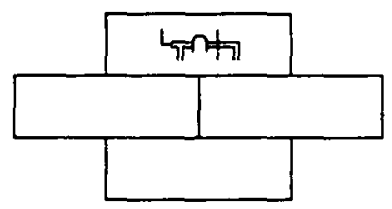

Figure 1. Sequence and timing of the four types of arrays in Experiment 1.
Of the 384 trials, the first 64 served both as practice and to prefamiliarize the observers with the repeated strings. The duration of exposure of the attention arrays on these trials was gradually reduced from $1 \mathrm{sec}$ on the 1st trial to $200 \mathrm{msec}$ by the 16th trial. On all remaining trials, the attention arrays were presented for $200 \mathrm{msec}$. Only the all-familiar arrays were presented on the prefamiliarization trials. The remaining 320 trials, deemed test trials, contained a random ordering of 80 all-familiar, 80 all-novel, and 160 one-novel arrays. Throughout the experiment, the presentation of familiar strings was constrained so that they were both displayed and probed for with approximately equal frequency. Additionally, novel and familiar strings were randomly assigned to array locations with the restriction that each type of string appear in, and be probed from, each array location equally often. Over all, the relative frequency with which novel and familiar strings were probed matched their relative frequencies of presentation. Thus, novel strings were probed for $25 \%$ of the time in one-novel arrays, and $100 \%$ of the time in all-novel arrays. Three independent constructions of the experiment were made, entailing different random assignments of strings to conditions and conditions to trials. Each construction was administered to 12 observers. For each construction, four randomly chosen strings served as familiar objects.

\section{Results and Discussion}

Throughout the study, a response was excluded from analysis if its latency was less than $250 \mathrm{msec}$ or greater than $6,000 \mathrm{msec}$. Approximately $1 \%$ of the data were dropped as a result of this criterion. All effects were considered statistically reliable at $p<.05$. In each of the present experiments, accuracy and latency of localization tended to inversely covary across the array conditions. However, owing to both the instructional emphasis on accuracy and the provision of accuracy feedback, response accuracy was more sensitive to the experimental manipulations than was response latency. Consequently, only the accuracy data are reported here. Further, because analyses assessing the impact of such auxiliary variables as probed location, particular string probed, and experimental construction revealed no interactions that compromised our conclusions, discussion is limited to the effects of the main experimental variables.

The data for Experiment 1 are summarized in Figure 2. As in previous studies, localization accuracy was higher for all-familiar arrays than for all-novel arrays $[F(1,35)=$ $\left.21.89, M S_{\mathrm{e}}=123.01\right]$. This finding replicates the usual perceptual advantage of familiar arrays and is attributable to the effects of priming and perceptual schemata. However, when a single novel string was introduced into a field of three familiar strings, localization accuracy for the novel string rose above that for all-novel arrays $\left[F(1,35)=7.79, M S_{e}=88.23\right]$, and accuracy for the familiar strings fell below that for all-familiar arrays $[F(1,35)$ $\left.=4.58, M S_{\mathrm{e}}=93.89\right]$. Localization accuracies for novel and familiar strings in the same array were statistically indistinguishable $(F<1.0)$.

The results of Experiment 1 show that both the novelpopout and familiar-sink-in effects observed by Johnston et al. $(1990,1993)$ are replicable with the use of nonsense strings as stimuli in lieu of words. Thus, these effects do not appear to be restricted to linguistic stimuli. Both the structure of the experimental trials and the postexperimen- 


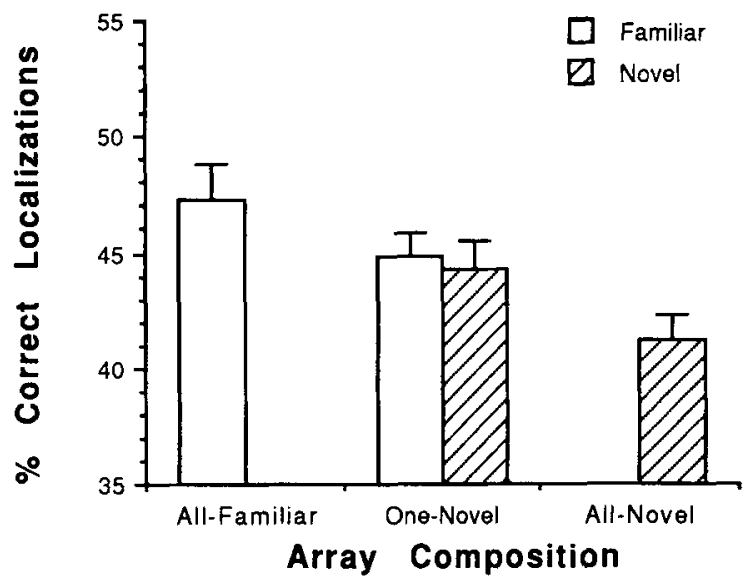

Figure 2. Localization accuracy for novel and familiar objects in Experiment 1 as a function of array composition. (Vertical bars represent standard errors.)

tal questionnaire data discredit an interpretation of these findings in terms of an explicit attempt to search for novel strings. First, the arrays were displayed for only $200 \mathrm{msec}$, so these effects are not attributable to eye fixation movements. Second, the novel strings were probed for on only $25 \%$ of the one-novel trials, so there was no probabilistic bias that might have fostered a search for these strings. Finally, analysis of the questionnaire data revealed that although $92 \%$ of the observers were aware that some stimuli were repeated during the experiment, only $25 \%$ professed any knowledge of the existence of one-novel arrays, and none of these reported any deliberate attempts to search for novel strings.

\section{EXPERIMENT 2}

Because the stimuli used in Experiment 1 were generally unfamiliar to the observers, it seems likely that the mechanisms that underlie novel popout can operate on the physical representations of stimuli alone. Further, because novel popout has been observed in arrays exposed for as briefly as $33 \mathrm{msec}$ (Johnston et al., 1993), it is possible that the perceptual dynamics that give rise to novel popout rely on some relatively simple physical feature to distinguish between novel and familiar strings. One obvious candidate for such a feature is string length. Although previous investigations of novel popout have attempted to minimize the impact of distinctive perceptual features by randomly assigning words to serve as novel and familiar stimuli, it is possible that novel popout occurs principally within the small percentage of trials in which novel stimuli happen to be noticeably longer or shorter than the familiar words that surround them. In Experiment 2, we sought to test this possibility.

In Experiment 2, two different sets of nonsense strings were employed. Strings in the first set varied randomly in terms of their length, whereas those in the second set were constant. Observers were randomly assigned to view one of these two sets at the start of the experiment. Thus, although some of the observers could occasionally use the simple featural cue of string length as an aid in identifying individual strings, others could not. Additionally, the number of prefamiliarization trials was increased from 64 to 122 for all the observers. Because previous studies have suggested that novel popout varies as a function of the interitem associations between familiar stimuli (Johnston et al., 1993), it was reasoned that the stronger interitem associations between familiar strings produced by this manipulation would engender a corresponding increase in the magnitude of novel popout.

\section{Method}

Observers and Design. A new sample of 72 observers was recruited in the same manner described in Experiment 1. Formally, the design was a $2 \times 3$ (length variability $\times$ array composition) mixed factorial, with repeated measures on the second factor. Stimulus type (novel vs. familiar) was a third factor nested within the one-novel arrays.

Equipment, Stimuli, and Procedure. The equipment and software were identical to those employed in Experiment 1. At the start of the experimental session, each observer was randomly assigned to one of two length variability groups. The strings viewed by the observers in the variable-length group were identical, in terms of their overall characteristics, to those employed in Experiment 1. For the observers in the constant-length group, a corresponding set of 384 strings was assembled by using the same procedure described in Experiment 1, but with the additional restriction that all the strings be limited to four characters in length. For each group, three independent constructions of the experiment were generated, and each construction was administered to 12 observers. All other procedures were identical to those employed in Experiment 1, with the exception that an additional 48 trials were added to the practice phase.

\section{Results and Discussion}

The results for Experiment 2 are summarized in Figure 3. With one exception, the same pattern of effects observed in Experiment 1 was duplicated in both of the groups of Experiment 2. As in Experiment 1, strings in all-familiar arrays were localized more accurately than those in all-novel arrays $\left[F(1,70)=56.15, M S_{\mathrm{e}}=44.60\right]$. Moreover, novel strings in one-novel arrays were localized more accurately than those in all-novel arrays $[F(1,70)=$ $\left.6.37, M S_{\mathrm{e}}=59.60\right]$, and familiar strings in one-novel arrays were localized less accurately than those in all-familiar arrays $\left[F(1,70)=7.99, M S_{e}=18.42\right]$. None of these effects interacted with the factor of length variability (all $F \mathrm{~s}<1.28$ ). These results reinforce the conclusion of Experiment 1 that novel popout is not limited to linguistic or otherwise meaningful stimuli. Further, because neither novel popout nor familiar sink-in interacted with the factor of length variability, the mechanisms upon which novel popout is based do not appear to rely on the simple feature of string length as a cue for discriminating between novel and familiar strings.

However, unlike Experiment 1, novel strings in the one-novel arrays of Experiment 2 were localized reliably less accurately than the familiar strings in those same ar- 

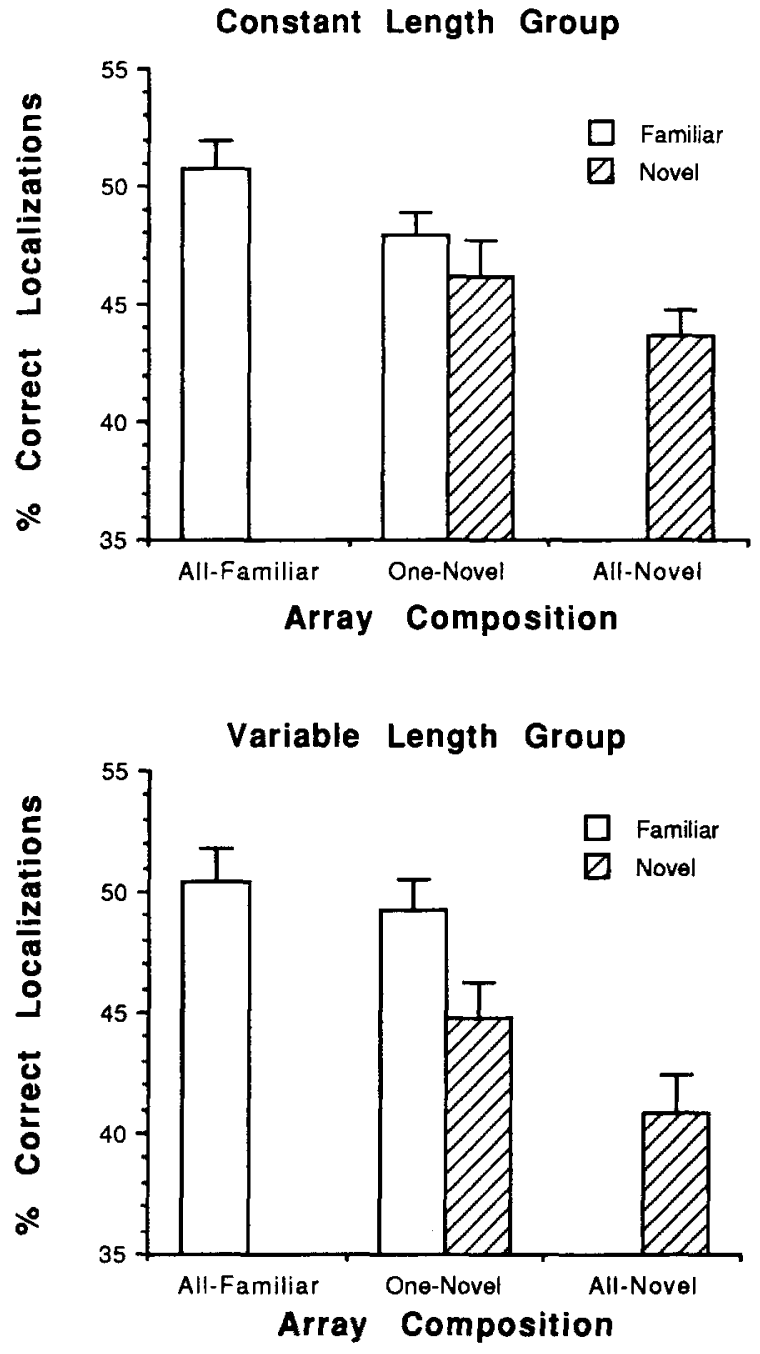

Figure 3. Localization accuracy for novel and familiar objects in Experiment 2 as a function of array composition for the constantand variable-length groups. (Vertical bars represent standard errors.)

rays $\left[F(1,70)=8.63, M S_{\mathrm{e}}=39.38\right]$. This effect also did not interact with the factor of length variability $[F(1,70)=$ $1.74, M S_{\mathrm{e}}=39.38 \mathrm{]}$. One possible explanation for this finding is that the higher number of practice trials that were employed in an effort to increase the magnitude of novel popout had the unanticipated effect of increasing the perceptibility of familiar strings. As a result, although attention was shifted toward the novel string in one-novel arrays, the enhanced processing of the novel string was not enough to overcome the perceptual advantage of the familiar strings in those arrays. A comparison of the localization accuracies for all-novel and all-familiar arrays in Experiments 1 and 2 tends to support this hypothesis. Although accuracies for all-novel arrays are statistically equivalent in both experiments $[t(70)=1.54, S E=1.13]$, all-familiar accuracies were somewhat higher in Experiment $2[t(70)=1.81, S E=1.39]$. Because all of the major effects associated with novel popout were evident in the present study, this enhanced perceptibility of familiar strings did not appear to alter the basic perceptual dynamics underlying novel popout. Thus, the results of Experiment 2 generally demonstrate that novel objects can capture attention even when they cannot be segregated from their perceptual field on the basis of the simple feature of length.

\section{EXPERIMENT 3}

The finding of significantly poorer localization accuracies for novel stimuli in one-novel arrays in spite of an apparent shift of attention toward those objects raises an interesting question about the relationship between novelpopout and schematic perception. Specifically, the findings of Experiment 2 suggest that although attention may be directed toward novel or incongruent stimuli during scene perception, this bias may not be enough to overcome the top-down perceptual advantage of familiar stimuli. Thus, although novel popout may produce a perceptual boost for novel stimuli, these stimuli may remain relatively imperceptible when briefly viewed in a highly familiar scene.

In examining the perceptibility of objects of varying congruency with their surroundings, other researchers have found novel or incongruent objects to be less perceptible than the familiar or congruent objects with which they appear (e.g., Biederman, Mezzanotte, \& Rabinowitz, 1982). This finding has been more pronounced when the novel objects appeared in some highly familiar setting such as a street scene, as opposed to a more abstract setting such as randomly arranged objects on a computer screen (e.g., Biederman, Blickle, Teitelbaum, \& Klatsky, 1988). Because objects in naturalistic scenes tend to be arranged in stable configurations, the locations of these objects could, to some extent, be inferred, thus inflating the likelihood of their correct localization. In addition to the topdown benefits provided by priming and schematic perception, this predictability would tend to ensure the superior localizability of familiar objects. However, the Biederman et al. (1982) study did not incorporate the equivalent of an all-novel baseline condition, so the extent to which novel objects in this study nonetheless benefited from a subtle shift of attention is not known. Thus, even though familiar objects are substantially more localizable than novel ones in highly familiar scenes, a subtle shift of attention toward novel objects in these settings may continue to occur.

In Experiment 3, we sought to determine whether the between-arrays effects indicative of novel popout continue to occur even when the locations of familiar objects are completely predictable. To achieve this, familiar strings were presented in one of two formats. In random arrays, familiar strings continued to be randomly assigned to array locations, but in fixed arrays, each familiar string always appeared in the same location. Observers were randomly assigned to view one of these two formats at the 
start of the experiment. Thus, although some of the observers could infer the locations of familiar strings, others could not. If higher levels of location predictability merely inflate localization accuracies for familiar objects without eliminating a capture of attention by novel stimuli, then both novel popout and familiar sink-in should be observed, even for fixed arrays.

\section{Method}

Observers and Design. A new sample of 72 observers was recruited from the same pool used in Experiments 1 and 2. The design was a $2 \times 3$ (array format $\times$ array composition) mixed factorial, with repeated measures on the second factor. String type (novel vs. familiar) continued to be a third factor nested within the one-novel arrays.

Equipment, Stimuli, and Procedure. The equipment and software were identical to those employed in Experiments 1 and 2. A new sample of 532 objects, which varied from four to seven characters in length, was generated by using the same procedure described in Experiment 1. At the start of the experiment, the observers were randomly assigned to one of the two array format groups. For the observers in the random-array group, the familiar strings were assigned randomly to locations. For the observers in the fixed-array group, each familiar string always appeared in the same spatial location. For each group, three independent constructions of the experiment, entailing different familiar strings and different orderings of probed location and array type, were made; each construction was administered to 12 observers.

In all, there were 484 experimental trials, including 116 practice trials and 368 test trials. The former trials consisted of 96 all-familiar and 20 all-novel arrays, and the latter trials consisted of 160 allfamiliar arrays, 128 one-novel arrays, and 80 all-novel arrays. All other procedures were identical to those employed in Experiments 1 and 2 .

\section{Results and Discussion}

The results for Experiment 3 are summarized in Figure 4. Although localization accuracies for all-familiar arrays were significantly higher than those for all-novel arrays in both of the groups $\left[F(1,70)=410.58, M S_{\mathrm{e}}=\right.$ 254.83], the strong interaction between this effect and the factor of array format confirmed what was expected and what is evident in Figure 4; namely, familiar objects were much more localizable when they appeared in fixed rather than in random formats $\left[F(1,70)=281.80, M S_{\mathrm{e}}=\right.$ 254.83]. However, in spite of the near-perfect localizability of familiar strings in the fixed format, both novel popout and familiar sink-in achieved statistical reliability in both of the groups. As Figure 4 shows, novel strings were localized more accurately when they appeared in one-novel as opposed to all-novel arrays $[F(1,70)=7.51$, $\left.M S_{\mathrm{e}}=147.33\right]$, and familiar strings in these arrays were localized less accurately than when they appeared in allfamiliar arrays $\left[F(1,70)=5.42, M S_{\mathrm{e}}=57.18\right]$. Neither of these effects interacted with the factor of array format (both $F \mathrm{~s}<1.0$ ). Moreover, although there was a significant main effect of string type within the one-novel arrays $\left[F(1,70)=237.84, M S_{\mathrm{e}}=312.44\right]$, this effect interacted strongly with the factor of array format $[F(1,70)$ $\left.=240.51, M S_{\mathrm{e}}=312.44\right]$. Post hoc tests revealed that although familiar strings were much more localizable than
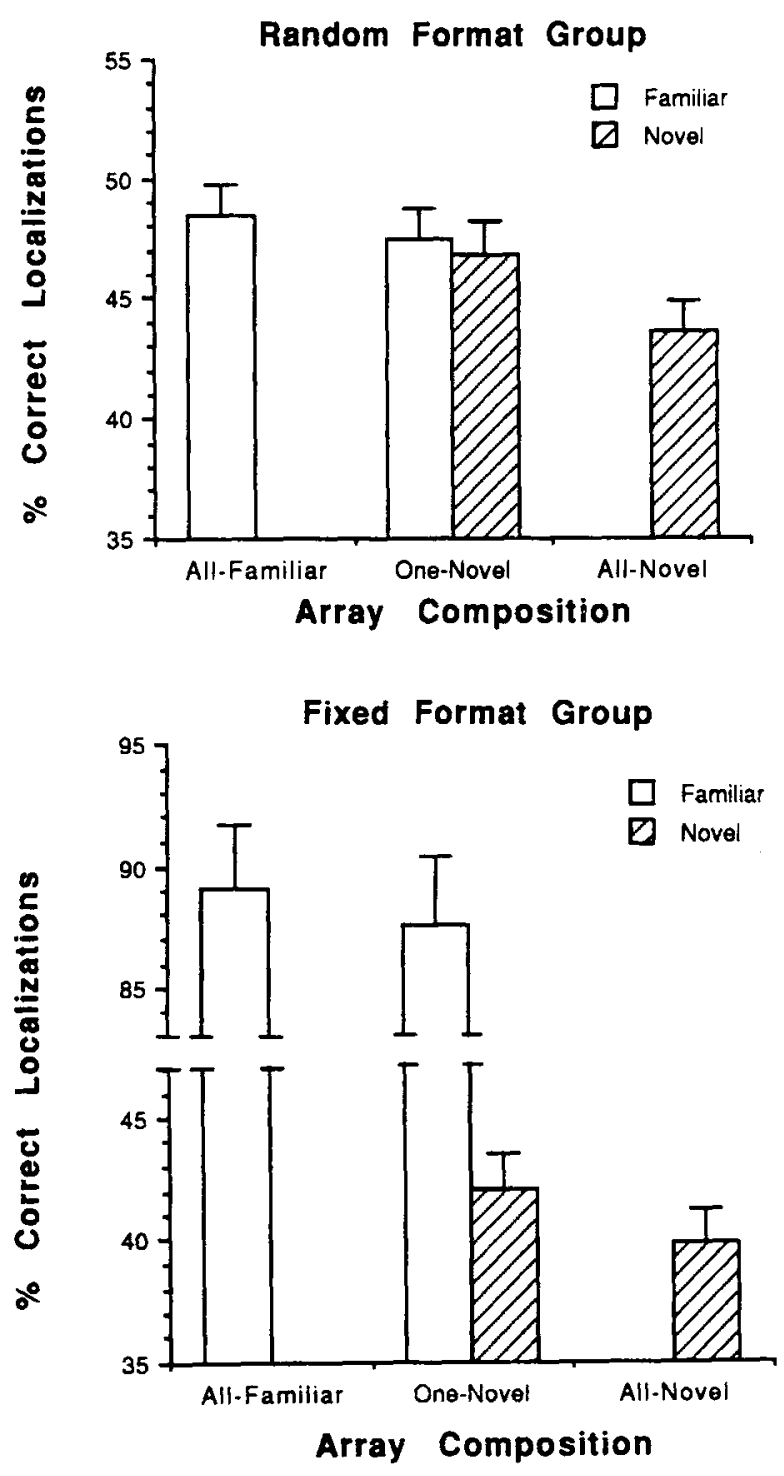

Figure 4. Localization accuracy for novel and familiar objects in Experiment 3 as a function of array composition for both array formats. Note that the ordinate axis for the fixed-format group has been broken to accommodate the higher localization accuracies for fixed familiar strings. (Vertical bars represent standard errors.)

the accompanying novel string in fixed-format one-novel arrays $[t(36)=16.94, S E=2.69]$, those in randomformat arrays were approximately equal to their novel counterparts $[t(36)=0.52, S E=1.29]$ in localizability. Collectively, these findings suggest that although localization accuracies for familiar objects are substantially enhanced by the location predictability inherent in stable, naturalistic scenes, this enhancement does not eliminate the shift of attention toward novel or unexpected objects in those scenes.

These findings are particularly remarkable in light of the highly unfavorable conditions for obtaining novel popout in the fixed-array group. Because the locations of 
familiar strings in this group are completely predictable, there is relatively little incentive for observers to rely on a detailed bottom-up analysis of arrays. Indeed, a comparison of localization accuracies for novel strings in the fixed and random groups revealed a significant drop in localization accuracy for novel strings in the fixed-format group $\left[F(1,70)=6.74, M S_{\mathrm{e}}=393.90\right]$, suggesting that the observers in this group relied less on bottom-up processing of the arrays than did those in the random-format group. Because the detection of perceptually incongruent information is presumably dependent on the bottom-up processing of an array or scene, the continued presence of novel popout under conditions in which bottom-up information is underutilized suggests that the mechanisms upon which novel popout is based require relatively little bottom-up information.

Finally, although the relative magnitudes of the novelpopout effects depicted in Figure 4 are small in comparison with the effect of location predictability, there are at least two reasons why this should not be considered to trivialize the impact of novel popout in scene perception. First, it is not clear that the absolute magnitude of novel popout in briefly exposed arrays directly corresponds to its long-term impact on perceptual processing. Although the perceptual enhancement resulting from a shift in attention toward novel objects in highly predictable scenes may not be enough to overcome the perceptual advantage of familiar objects, the perceptual boost accorded this object may still be sufficient to both enhance its subsequent perceptibility and to facilitate the formation of associative links between that object and the familiar objects that surround it. In turn, across multiple exposures to the same scenes, these processes may be sufficient to allow a slow but continuous updating of perceptual schemata in response to environmental change. Second, although the present findings suggest that novel objects are substantially less perceptible than familiar ones when briefly viewed in highly predictable arrays, there is considerable evidence that longer viewing time of such arrays results in novel stimuli's being both recalled and recognized more accurately than their familiar counterparts (Bower, Black, \& Turner, 1979; Friedman, 1979; Mäntylä \& Bäckman, 1992; Pezdek, Whetstone, Reynolds, Askari, \& Dougherty, 1989). Thus, the relatively small novel-popout effect observed in Experiment 3 may in fact reflect the initial stages of a more detailed level of perceptual processing wherein strong memorial traces for stimuli that are incongruent with their surroundings are established.

\section{GENERAL DISCUSSION}

In the present research, we investigated some of the conditions under which attention is captured by novel or unexpected stimuli. If, as suggested by Johnston et al. (1990), the capture of attention by novel stimuli counteracts the biasing effects of schematic perception, then a broader understanding of the conditions under which this effect operates is crucial to the development of more com- plete theories of perceptual processing. The results of the present experiments attest to the generality and robustness of novel popout.

The present research extends the research on novel popout in several ways. First, each of the present experiments demonstrates that novel popout can be obtained with the use of nonsense strings as stimuli, in lieu of words. Novel popout in these experiments was manifested both as a higher accuracy of localization for novel strings in onenovel arrays versus those in all-novel arrays, and as lower accuracies for familiar strings in one-novel arrays versus those in all-familiar arrays. These findings show that novel popout is not limited to stimuli with well-established meanings, such as the words employed in our previous studies (Johnston et al., 1990, 1993). Rather, they suggest that novel popout is a relatively general perceptual phenomenon in which attention is captured by any object that is incongruent with the scene in which it appears. Moreover, because the stimuli used in the present experiments were generally unfamiliar to subjects, it seems likely that the mechanisms that underlie novel popout can operate on the physical representations of stimuli alone.

A second finding that emerges from the present study is the observation that novel popout can occur under conditions that lessen reliance on bottom-up perceptual information (e.g., the fixed-array group of Experiment 3). This finding suggests that novel popout holds up over a wide range of levels of bottom-up processing for an array or scene. Further, because the locations of familiar strings in fixed arrays were completely predictable, novel popout does not appear to be based on any perceptual or memorial confusion regarding the locations of familiar objects. Finally, the observation that there is novel popout when the length of novel and familiar strings is held constant, thus removing the simple feature of string length as a cue for discriminating between stimuli, suggests that novel popout entails a more detailed perceptual analysis of novel and familiar strings than a simple discrimination based on string length. Altogether, these findings generally reinforce the view that novel popout is a relatively basic and robust perceptual phenomenon.

As indicated by the results of Experiment 3, increases in the spatial predictability of familiar strings tend to produce concomitant increases in localization accuracy for those strings. One effect of this increase is that familiar strings are localized considerably more accurately when they appear in a predictable format than when they appear in a random format. This difference extends to arrays in which a single novel string is introduced, so that familiar strings in highly predictable arrays are localized more accurately than the novel string that appears in their midst. However, in spite of this enhanced localizability of familiar over novel strings in highly predictable onenovel arrays, novel strings in these arrays continue to benefit from a shift of attention. This shift is manifest both as lower localization accuracies for familiar strings in onenovel arrays versus those in all-familiar arrays and as higher accuracies for the novel string in these arrays 
versus those in all-novel arrays. This suggests that novel popout continues to operate in, and is relatively undiminished by, situations in which the identities and locations of familiar objects are highly predictable. Because longer periods of array exposure are known to produce a marked enhancement in both recall and recognition for novel stimuli, it seems likely that this shift reflects the initial stages of a more intensive processing of those stimuli.

In summary, the present studies reinforce the view of novel popout as a relatively basic, primitive, and robust perceptual phenomenon in which objects that are incongruent with their surroundings capture attention. Given both the generality of the effect and its agreement with studies demonstrating increased recall and recognition for novel versus familiar stimuli, it seems likely that novel popout acts as a persistent and substantial counterweight to the biasing effects of priming and perceptual schemata. If the shift of attention toward novel stimuli fosters the integration of those stimuli within existing perceptual schemata, then novel popout may substantially increase the survival potential of organisms by allowing them to constantly detect and adapt to changes in their environment.

\section{REFERENCES}

Biederman, I. (1972). Perceiving real-world scenes. Science, 177, 77-80.

Biederman, I., Blickle, T. W., Teitelbaum, R. C., \& Klatsky, G. J. (1988). Object search in nonscene displays. Journal of Experimental Psychology: Learning, Memory, \& Cognition, 14, 456-467.

Biederman, 1., Mezzanotte, R. J., \& Rabinowitz, J. (1982). Scene perception: Detecting and judging objects undergoing relational violations. Cognitive Psychology, 14, 143-177.

BOWER, G. H., BLACK, J. B., \& TuRNER, T. J. (1979). Scripts in memory for text. Cognitive Psychology, 11, 207-230.

Feustal, T. C., Shiffrin, R. M., \& Salasoo, A. (1983). Episodic and lexical contributions to the repetition effect in word identification. Journal of Experimental Psychology: General, 112, 309-346.

Friedman, A. (1979). Framing pictures: The role of knowledge in automatized encoding and memory for gist. Joumal of Experimental Psychology: General, 108, 316-355.

HAWLEY, K. J. (1991). PsyExper: Another experimental generation system for the IBM PC. Behavior Research Methods, Instruments, \& Computers, 23, 155-159.

JACOBY, L. L., \& DALLAS, M. (1981). On the relationship between autobiographical memory and perceptual learning. Joumal of Experimental Psychology: General, 3, 300-324.
Johnston, W. A., Hawley, K. J., \& Farnham, J. M. (1993). Novel popout: Empirical boundaries and tentative theory. Joumal of Experimental Psychology: Human Perception \& Performance, 19, 140-153.

Johnston, W. A., Hawley, K. J., Plewe, S. H., Elliott, J. M. G., \& DEWITT, M. J. (1990). Attention capture by novel stimuli. Journal of Experimental Psychology: General, 119, 397-411.

JoNIDES, J., \& YANTIS, S. (1988). Uniqueness of abrupt visual onset in capturing attention. Perception \& Psychophysics, 43, 346-354.

MANDLER, J. M. (1984). Stories, scripts, and scenes: Aspects of schema theory. Hillsdale, NJ: Erlbaum.

MäNTYLÄ, T., \& B̈̈CKMAN, L. (1992). Aging and memory for expected and unexpected objects in real-world settings. Journal of Experimental Psychology: Learning, Memory, \& Cognition, 18, 1298-1309.

Meyers, D. E., SchVaneveldt, R. W., \& Ruddy, M. G. (1975). Loci of contextual effects on visual word recognition. In P. M. A. Rabbit \& S. Dornic (Eds.), Attention and performance V (pp. 98-118). London: Academic Press.

Pezdek, K., Whetstone, T., Reynolds, K., Askari, N., \& DoughERTY, T. (1989). Memory for real-world scenes: The role of constancy and expectation. Journal of Experimental Psychology: Learning, Memory, \& Cognition, 15, 587-595.

Rumelhart, D. E., Smolensky, P., McClelland, J. L., \& Hinton, G. E. (1986). Schemata and sequential thought processes in PDP models. In J. L. McClelland \& D. E. Rumelhart (Eds.), Parallel distributed processing (pp. 7-57). Cambridge: MIT Press.

\section{NOTE}

1. Our use of the phrase novel popout may be misleading in light of the fact that novel stimuli achieve absolute perceptual dominance over familiar stimuli only in the case of the within-array effect. As it was originally used in Johnston et al. (1990), the term novel popout was intended to denote the capture of attention by any novel or unexpected stimulus in an array of otherwise familiar or expected stimuli. We recognize that the term is somewhat confusing in that it is arguable that attention capture and popout are not synonymous terms (see Jonides \& Yantis, 1988). However, in order to avoid generating a redundant vocabulary to describe the previously reported findings on novel popout, we have chosen to employ the original descriptive terms developed by Johnston et al. (1990). Thus, throughout this paper, the term novel popout is used to denote a shift of attention toward any novel or unexpected stimulus within an array or scene as indexed by an increase in localization accuracy for that stimulus relative to other novel stimuli appearing in all-novel arrays.

(Manuscript received January 29, 1993; revision accepted for publication July 24,1993 .) 